\title{
GUARANTEED ANNUITY OPTIONS
}

BY

\author{
Phelim Boyle And Mary Hardy ${ }^{1}$
}

\begin{abstract}
Under a guaranteed annuity option, an insurer guarantees to convert a policyholder's accumulated funds to a life annuity at a fixed rate when the policy matures. If the annuity rates provided under the guarantee are more beneficial to the policyholder than the prevailing rates in the market the insurer has to make up the difference. Such guarantees are common in many US tax sheltered insurance products. These guarantees were popular in UK retirement savings contracts issued in the 1970's and 1980's when long-term interest rates were high. At that time, the options were very far out of the money and insurance companies apparently assumed that interest rates would remain high and thus that the guarantees would never become active. In the 1990's, as long-term interest rates began to fall, the value of these guarantees rose. Because of the way the guarantee was written, two other factors influenced the cost of these guarantees. First, strong stock market performance meant that the amounts to which the guarantee applied increased significantly. Second, the mortality assumption implicit in the guarantee did not anticipate the improvement in mortality which actually occurred.

The emerging liabilities under these guarantees threatened the solvency of some companies and led to the closure of Equitable Life (UK) to new business. In this paper we explore the pricing and risk management of these guarantees.
\end{abstract}

\section{INTRODUCTION}

\subsection{An introduction to guaranteed annuity options}

Insurance companies often include very long-term guarantees in their products which, in some circumstances, can turn out to be very valuable. Historically these options, issued deeply out of the money, have been viewed by some insurers as having negligible value. However for a very long dated option, with a term of perhaps 30 to 40 years, there can be significant fluctuations in economic variables, and an apparently negligible liability can become very substantial. The case of guaranteed annuity options (GAOs) in the UK provides a dramatic illustration of this phenomenon.

1 Both authors acknowledge the support of the National Science and Engineering Research Council of Canada. 
Guaranteed annuity options have proved to be a significant risk management challenge for several UK insurance companies. Bolton et al (1997) describe the origin and nature of these guarantees. They also discuss the factors which caused the liabilities associated with these guarantees to increase so dramatically in recent years. These factors include a decline in long-term interest rates and improvements in mortality. For many contracts the liability is also related to equity performance and in the UK common stocks performed very well during the last two decades of the twentieth century.

Under a guaranteed annuity the insurance company guarantees to convert the maturing policy proceeds into a life annuity at a fixed rate. Typically, these policies mature when the policyholder reaches a certain age. In the UK the most popular guaranteed rate for males, aged sixty five, was $£ 111$ annuity per annum per $£ 1000$ of cash value, or an annuity:cash value ratio of 1:9 and we use this rate in our illustrations. If the prevailing annuity rates at maturity provide an annual payment that exceeds $£ 111$ per $£ 1000$, a rational policyholder would opt for the prevailing market rate. On the other hand, if the prevailing annuity rates at maturity produce a lower amount than $£ 111$ per $£ 1000$, a rational policyholder would take the guaranteed annuity rate. As interest rates rise the annuity amount purchased by a lump sum of $£ 1000$ increases and as interest rates fall the annuity amount available per $£ 1000$ falls. Hence the guarantee corresponds to a put option on interest rates. In Sections two, three and four we discuss the option pricing approach to the valuation of GAOs.

These guarantees began to be included in some UK pension policies in the 1950 's and became very popular in the 1970's and 1980's. In the UK the inclusion of these guarantees was discontinued by the end of the 1980's but, given the long-term nature of this business, these guarantees still affect a significant number of contracts. Long-term interest rates in many countries were quite high in 1970's and 1980's and the UK was no exception. During these two decades the average UK long-term interest rate was around $11 \%$ p.a. The interest rate implicit in the guaranteed annuity options depends on the mortality assumption but based on the mortality basis used in the original calculations the break-even interest rate was in the region of 5\%-6\% p.a. When these options were granted, they were very far out of the money and the insurance companies apparently assumed that interest rates would never fall to these low levels again ${ }^{2}$ and thus that the guarantees would never become active. As we now know this presumption was incorrect and interest rates did fall in the 1990's.

The guaranteed annuity conversion rate is a function of the assumed interest rate and the assumed mortality rate. Bolton et al note that when many of these guarantees were written, it was considered appropriate to use a mortality table with no explicit allowance for future improvement such as a(55). This is a mortality table designed to be appropriate for immediate life annuities purchased in 1955, but was still in vogue in the 1970s. However, there was a dramatic improvement in the mortality of the class of lives on which these guarantees were written during the period 1970-2000. This improvement meant

2 Although interest rates were of this order for part of the 1960s. 
that the break-even interest rate at which the guarantee kicked in rose. For example, for a 13-year annuity-certain, a lump sum of 1000 is equivalent to an annual payment of $111 \mathrm{p}$.a. at $5.70 \%$. If we extend the term of the annuity to sixteen years the interest rate rises to $7.72 \%$. Hence, if mortality rates improve so that policyholders live longer, the interest rate at which the guarantee becomes effective will increase. In Section 2 we will relate these break-even rates to appropriate UK life annuity rates.

\subsection{A typical contract}

To show the nature of the GAO put option we use standard actuarial notation, adapted slightly. Assume we have a single premium equity-linked policy. The contract is assumed to mature at $T$, say, at which date the policyholder is assumed to be age 65. The premium is invested in an account with market value $S(t)$ at time $t$, where $S(t)$ is a random process. The market cost of a life annuity of $£ 1$ p.a. for a life age 65 is also a random process. Let $a_{65}(t)$ denote this market price.

The policy offers a guaranteed conversion rate of $g=9$. This rate determines the guaranteed minimum annuity payment per unit of maturity proceeds of the contract; that is, $£ 1$ of the lump sum maturity value must purchase a minimum of $£ 1 / g$ of annuity.

At maturity the proceeds of the policy are $S(T)$; if the guarantee is exercised this will be applied to purchase an annuity of $S(T) / g$, at a cost of $(S(T) / g) a_{65}(T)$. The excess of the annuity cost over the cash proceeds must be met by the insurer, and will be

$$
\frac{S(T)}{g} a_{65}(T)-S(T)
$$

If $a_{65}(T)<9$ the guarantee will not be exercised and the cash proceeds will be annuitized without additional cost.

So, assuming the policyholder survives to maturity, the value of the guarantee at maturity is

$$
S(T) \max \left[\left(\frac{a_{65}(T)}{g}-1\right), 0\right]
$$

The market annuity rate $a_{65}(t)$ will depend on the prevailing long-term interest rates, the mortality assumptions used and the expense assumption. We will ignore expenses and use the current long-term government bond yield as a proxy for the interest rate assumption. We see that the option will be in-the-money whenever the current annuity factor exceeds the guaranteed factor, which is $g=9$ in the examples used in this paper.

We see from equation (1) that, for a maturing policy, the size of the option liability will be proportional to $S(T)$ : the amount of proceeds to which the guarantee applies. The size of $S(T)$ will depend on the nature of the contract 
and also on the investment returns attributed to the policy. The procedure by which the investment returns are determined depends on the terms of the policy. Under a traditional UK with profits contract profits are assigned using reversionary bonuses and terminal bonuses. Reversionary bonuses are assigned on a regular basis as guaranteed additions to the basic maturity value and are not distributed until maturity. Terminal bonuses are declared when the policy matures such that together with the reversionary bonuses, the investment experience over the term of the contract is (more or less) fully reflected. The size of the reversionary bonuses depends both on the investment performance of the underlying investments and the smoothing convention used in setting the bonus level. The terminal bonus is not guaranteed but during periods of good investment performance it can be quite significant, sometimes of the same order as the basic maturity sum assured. Bolton et al (1997) estimate that with profits policies account for eighty percent of the total liabilities for contracts which include a guaranteed annuity option. The remaining contracts which incorporate a guaranteed annuity option were mostly unit-linked policies.

In contrast to with profits contracts, the investment gains and losses under a unit-linked (equity-linked) contract are distributed directly to the policyholder's account. Contracts of this nature are more transparent than with profits policies and they have become very popular in many countries in recent years. Under a unit-linked contract the size of the option liability, if the guarantee is operative, will depend directly on the investment performance of the assets in which the funds are invested. In the UK there is a strong tradition of investing in equities and during the twenty year period from 1980 until 2000 the rate of growth on the major UK stock market index was a staggering $18 \%$ per annum.

In this paper we consider unit-linked policies rather than with profits. Unitlinked contracts are generally well defined with little insurer discretion. With profits policies would be essentially identical to unit-linked if there were no smoothing, and assuming the asset proceeds are passed through to the policyholder, subject to reasonable and similar expense deductions. However, the discretionary element of smoothing, as well as the opaque nature of the investment policy for some with profits policies make it more difficult to analyse these contracts in general. However, the methods proposed for unit-linked contracts can be adapted for with profits given suitably well defined bonus and asset allocation strategies.

\subsection{Principal factors in the GAO cost}

Three principal factors contributed to the growth of the guaranteed annuity option liabilities in the UK over the last few decades. First, there was a large decline in long-term interest rates over the period. Second, there was a significant improvement in longevity that was not factored into the initial actuarial calculations. Third, the strong equity performance during the period served to increase further the magnitude of the liabilities. It would appear that these events were not considered when the guarantees were initially granted. The responsibility for long-term financial solvency of insurance companies rests 
with the actuarial profession. It will be instructive to examine what possible risk management strategies could have been or should have been employed to deal with this situation. It is clear now with the benefit of hindsight that it was imprudent to grant such long-term open ended guarantees of this type.

There are three main methods of dealing with the type of risks associated with writing financial guarantees. First, there is the traditional actuarial reserving method whereby the insurer sets aside additional capital to ensure that the liabilities under the guarantee will be covered with a high probability. The liabilities are estimated using a stochastic simulation approach. The basic idea is to simulate the future using a stochastic model ${ }^{3}$ of investment returns. These simulations can be used to estimate the distribution of the cost of the guarantee. From this distribution one can compute the amount of initial reserve so that the provision will be adequate, say, $99 \%$ of the time. The second approach is to reinsure the liability with another financial institution such as a reinsurance company or an investment bank. In this case the insurance company pays a fee to the financial institution and in return the institution agrees to meet the liability under the guarantee. The third approach is for the insurance company to set up a replicating portfolio of traded securities and adjust (or dynamically hedge) this portfolio over time so that at maturity the market value of the portfolio corresponds to the liability under the guaranteed annuity option.

Implementations of these three different risk management strategies have been described in the literature. Yang (2001) and Wilkie, Waters and Yang (2003) describe the actuarial approach based on the Wilkie model. Dunbar (1999) provides an illustration of the second approach. The insurance company, Scottish Widows offset its guaranteed annuity liabilities by purchasing a structured product from Morgan Stanley. Pelsser (2003) analyzes a hedging strategy based on the purchase of long dated receiver swaptions. This is described more fully in Section 8.

In this paper we will discuss a number of the issues surrounding the valuation and risk management of these guarantees. We will also discuss the degree to which different risk management approaches would have been possible from 1980 onwards.

\subsection{Outline of the paper}

The layout of the rest of the paper is as follows. Section two provides background detail on the guaranteed annuity options and the relevant institutional framework. We examine the evolution of the economic and demographic variables which affect the value of the guarantee. In particular we provide a time series of the values of the guarantee at maturity for a representative contract. In Section three we use an option pricing approach to obtain the market price of the guarantee. Section Four documents the time series of market values of the guarantee. Using a simple one-factor model it is possible to estimate the

3 One such model, the Wilkie Model was available in the UK actuarial literature as early as 1980 . See MGWP(1980). 
market value of the option. Section five examines a number of the conceptual and practical issues involved in dynamic hedging the interest rate risk. Sections six and seven explore the issues involved in hedging the equity risk and the mortality risk. One suggestion for dealing with these guarantees involves the insurer purchasing long dated receiver swaptions. We describe this approach in Section eight. Section nine comments on the lessons to be learned from this episode.

\section{Maturity Value of the Guarantee}

In this section we document the evolution of the emerging liability under the guaranteed annuity option. Specifically we examine the magnitude of the guarantee for a newly maturing policy over the last two decades. In these calculations the policy proceeds at maturity are assumed to be held constant at $£ 100$, so the cost reported is the cost \% of the policy maturity cash value. We assume the annuity purchased with the policy proceeds is payable annually in arrear to a life age 65 at maturity, and has a five year guarantee period.

We consider three different mortality tables to determine the GAO cost.

- The a(55) mortality table represents the mortality assumptions being used in the 1970's to price immediate annuities. As previously mentioned, it was calculated to be appropriate to lives purchasing immediate annuities in 1955.

- The PMA80(C10) table from this series is based on UK experience for the period 1979-1982 and is projected to 2010 to reflect mortality improvements. The PMA80 series became available in 1990.

- The PMA92 series was published in 1998 and the table we use, the PMA92 (C20) table, is based on UK experience for the period 1991-1994, projected to 2020 to reflect mortality improvements.

The improvement from the a(55) table to the PMA92(C20) provides an upper bound on the mortality improvement over the period since the last named table only appeared at the end of the period and includes a significant projection for future mortality improvements. Wilkie Waters and Yang (2003) give a detailed account of the year by year relevant UK male mortality experience for the period 1984 to 2001 .

The increase in longevity is quite dramatic over the period covered by these three tables. The expectation of life for a male aged 65 is 14.3 years using a(55) mortality, 16.9 years under the PMA80(C10) table and 19.8 years under the PMA92(C20) table. Thus the expected future lifetime of a male aged 65 increased by 2.6 years from the a(55) table to the PMA80(C10) table. More dramatically the expected future lifetime of a male aged 65 increased by over five years from the a(55) table to the PMA92(C20) table.

On the basis of the a(55) mortality table, the break-even interest rate for a life annuity. is $5.61 \%$. That is, on this mortality basis a lump sum of 1000 will purchase an annuity of 111 at an interest rate of $5.61 \%$ p.a. effective. The guarantee will be in the money if long-term interest rates are less than $5.61 \%$. 


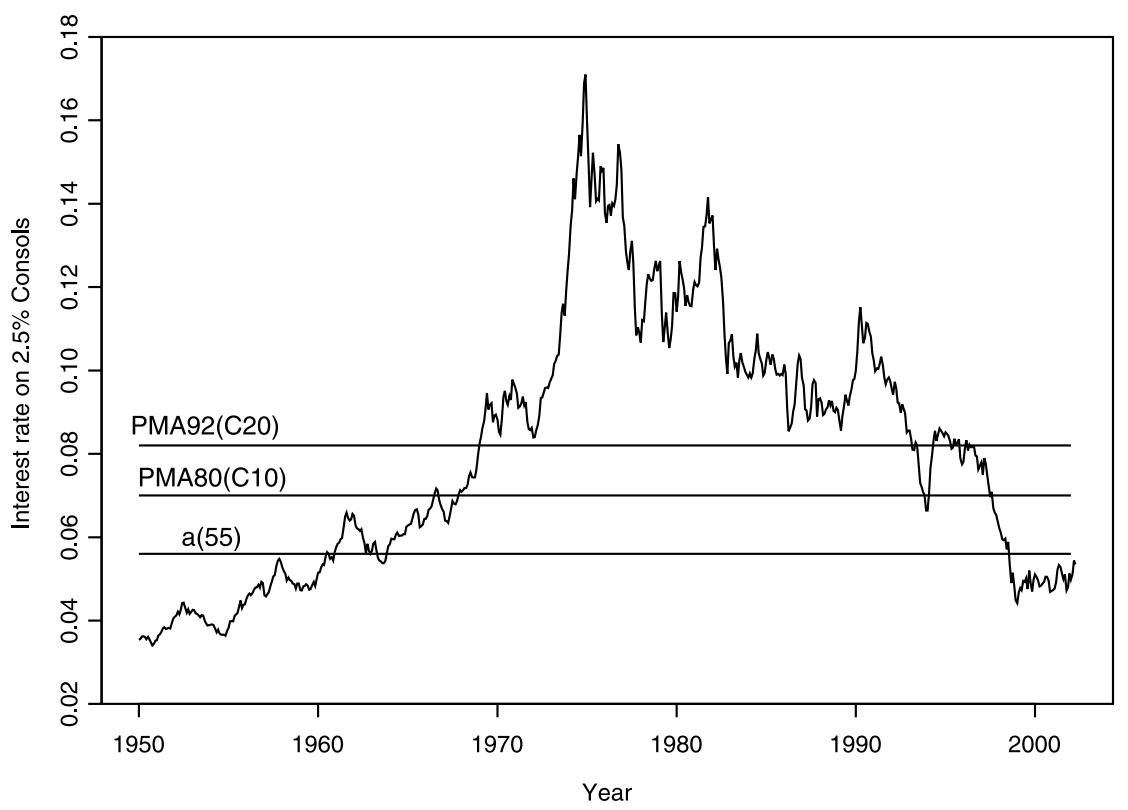

Fig 1: UK long-term interest rates 1950-2002, with interest rates levels that will trigger the guarantee for mortality tables a(55), PMA82(C10), PMA90(C20).

As a consequence of the mortality improvement the cost of immediate annuities increased significantly over this period independently of the impact of falling interest rates. Under the PMA80 $(\mathrm{C} 10)$ table the break-even rate is $7.0 \%$, and under the PMA92(C20) table it is $8.2 \%$.

Figure 1 illustrates the behavior of long-term interest rates in the UK since 1950. We note that rates rose through the later 1960s, remained quite high for the period 1970-1990 and started to decline in the 1990s. There was a large dip in long rates at the end of 1993 and long rates first fell below 6\% in 1998 and have hovered in the 4\%-6\% range until the present ${ }^{4}$ time. We also show in this figure the break-even interest rates for the GAO according to the three mortality tables.

Bolton et al (1997) provide extensive tables of the break even interest rates for different types of annuities and different mortality tables. They assume a two percent initial expense charge which we do not include. Thus in their Table 3.4 the value for the break even interest rate for a male aged 65 for an annuity of 111 payable annually in arrear with a five year guarantee is $5.9 \%$. This is consistent with our figure of $5.6 \%$ when we include their expense assumption.

The increase in the level of the at-the-money interest rate has profound implications for the cost of a maturing guaranteed annuity option. For example, if the long-term market rate of interest is $5 \%$, the value of the option for a

4 Early in 2003 at the time of writing. 


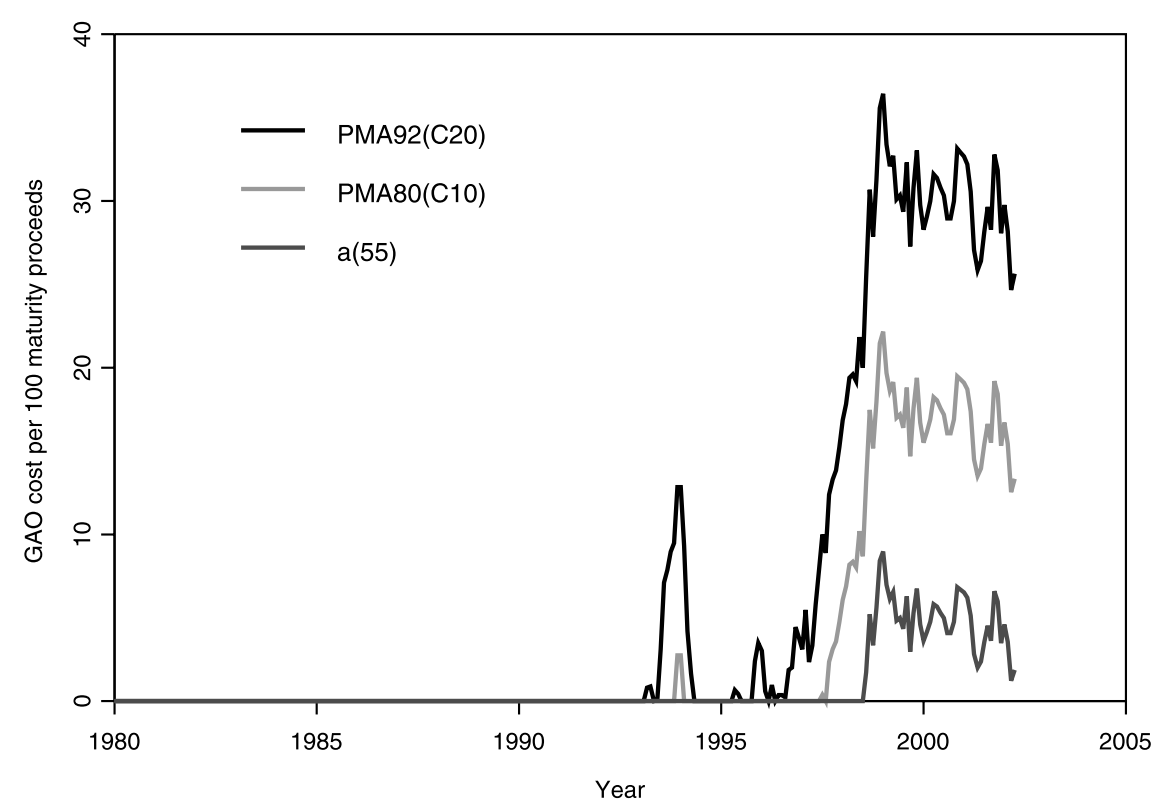

Fig 2: Value of maturing guarantee per 100 proceeds based on PMA92(C20), PMA80(C10), and a(55) mortality.

maturing policy with $£ 100$ maturity proceeds, based on a(55) is $£ 4.45$; based on PMA80(C10) it would be $£ 16.53$ and the corresponding value based on PMA92(C20) is $£ 29.52$. Note that we do not need any type of option formula to perform these calculations; we apply equation (1), with $S(T)$ fixed at 100 , and $a_{65}(T)$ calculated using the appropriate mortality and an interest rate of $5 \%$ per year. Figure 2 shows the magnitude of the option liability for our benchmark contract under the three mortality assumptions using historical interest rates. Since the long-term interest rate is the main determinant of the annuity cost, we have used the yield on $2.5 \%$ consols, which are government bonds, generally considered irredeemable ${ }^{5}$.

There is no liability on maturing contracts until the 1990's. Also note that the mortality assumption has a profound impact on the size of the liability.

We have already noted that during the period 1980-2000, UK equities performed extremely well. This resulted in increased levels of bonus to the with profits polices. For many contracts this meant that the volume of proceeds to which the guarantee applied also increased, thereby increasing the liability under the guarantee. In the case of unit-linked polices the gains are passed directly to the policyholder, apart from the various expenses. If we assume that a unit-linked contract earned the market rate of 18\% minus 300 basis points this still leaves a return of $15 \%$. At this growth rate an initial single

5 In fact they may be redeemed at any time at the discretion of the Exchequer. 
premium of $£ 100$ will accumulate to $£ 1636.7$ after twenty years. This growth would be proportionately reflected in the cost of the guarantee.

To summarize, we have discussed the evolution of the value of the liability for a sequence of maturing contracts. This analysis indicates how the three factors:

- The fall in long-term interest rates

- The improvement in mortality

- The strong equity performance

served to increase the cost of the guarantee. Note that our analysis in this section did not require any stochastic analysis or option pricing formula. We simply computed the value of the option at maturity each year of the period. In the next section we discuss the evaluation of these options prior to maturity.

\section{Derivation of an Option Formula}

\subsection{Introduction}

The guaranteed annuity option is similar to a call option on a coupon bond; the annuity payments and survival probabilities can be incorporated in the notional coupons.

First we develop the option formula without assuming a specific model for interest rates. Then, we will apply the Hull-White (1990) interest rate model (also known as extended Vasicek, from the Vasicek (1977) model) to calculate prices for the options.

We assume that the mortality risk is independent of the financial risk and that it is therefore diversifiable. In this case it is well documented (see, for example, Boyle and Schwartz (1977)) that it is appropriate to use deterministic mortality for valuing options dependent on survival or death.

\subsection{The numeraire approach}

Using stochastic interest rates, the price at some future date $t$ of a zero coupon bond with unit maturity value, maturing at $T$ is a random variable which we denote $D(t, T)$. The term structure of interest rates at $t$ is therefore described by the function $\{D(t, T)\}_{T>t}$. This term structure is assumed to be known at time $t$.

So, the actuarial value at $T$ of an immediate annuity payable to a life aged $x r$ at $T$, contingent on survival, is

$$
a_{x r}(T)=\sum_{j=1}^{J}{ }_{j} p_{x r} D(T, T+j)
$$

where ${ }_{j} p_{x r}$ represents the appropriate survival probability. For an annuity with an initial guarantee period of, say five years, we set the first five values of ${ }_{j} p_{x r}$ 
to 1.0. The limiting age of the mortality table is denoted by $\omega$ and we set $J=$ $(\omega-x r)$. Note that in valuing the annuity at $T$, the term structure is known, and there are no random variables in this expression.

Now, to value this expression at time $t<T$, we use a 'numeraire' approach. In the absence of arbitrage any market price deflated by a suitable numeraire is a martingale. We can use any traded asset which has a price that is always strictly positive as numeraire. Here we use the zero coupon bond which matures at time $T$ as the numeraire and we denote the associated probability measure by the symbol $Q_{T}$. This is often called the 'forward measure'. If interest rates are constant, it is the same as the risk neutral measure in the standard BlackScholes framework. See Björk (1998) for more details.

Suppose $V(s)$ is the market value at $s$ of some payoff occurring at some time $T+j, j \geq 0$. We use $D(s, T)$ as the numeraire, where $s \leq T$. The martingale result means that $X_{s}=\frac{V(s)}{D(s, T)}$ is a martingale under $Q_{T}$, so that $E_{Q T}\left[X_{s} \mid \mathcal{F}_{t}\right]=X_{t}$ for any $s$ such that $t \leq s \leq T$. Here $\mid \mathcal{F}_{t}$ indicates that we are taking expectation of the random process at time $t+k$ given all the relevant information at $t$. In particular at $t$ we know all values of $D(t, s), s \geq t$.

Applying this to take expectation of the ratio $\frac{V(s)}{D(s, T)}$ at $T$, and using the fact that $D(T, T)=1.0$, we have:

$$
\begin{aligned}
& \frac{V(t)}{D(t, T)}=E_{Q_{T}}\left[\frac{V(T)}{D(T, T)} \mid \mathcal{F}_{t}\right]=E_{Q_{T}}\left[V(T) \mid \mathcal{F}_{t}\right] \\
& \Rightarrow V(t)=D(t, T) E_{Q_{T}}\left[V(T) \mid \mathcal{F}_{t}\right]
\end{aligned}
$$

Equation (4) provides a valuation formula at $t$ for any payoff $V(T)$. The distribution $Q_{T}$ depends on the assumption made for interest rates, and we will discuss this later.

Now for the GAO we know from equation (1) that the payoff at maturity is ${ }^{6}$

$$
V(T)=\frac{S(T)\left(a_{x r}(T)-g\right)^{+}}{g}
$$

This is required for each policyholder surviving to time $T$, so to value at $t<T$ we multiply by the appropriate survival probability.

Then if $G(t)$ is the value of this benefit at $t$, and letting $x=x r-(T-t)$ we have:

$$
\begin{aligned}
& G(t)={ }_{T-t} p_{x} D(t, T) E_{Q_{T}}\left[V(T) \mid \mathcal{F}_{t}\right] \\
& \Rightarrow G(t)={ }_{T-t} p_{x} D(t, T) E_{Q_{T}}\left[\frac{S(T)\left(a_{x r}(T)-g\right)^{+}}{g} \mid \mathcal{F}_{t}\right]
\end{aligned}
$$

${ }^{6}$ We use $(X)^{+}=\max (X, 0)$. 
Initially we assume that $S(T)$ is independent of interest rates. This is a very strong assumption but it simplifies the analysis. Later we allow for correlation between equity returns and interest rates.

We have then:

$$
\begin{aligned}
G(t) & =\frac{{ }_{T-t} p_{x} D(t, T) E_{Q_{T}}[S(T)]}{g} E_{Q_{T}}\left[\left(a_{x r}(T)-g\right)^{+} \mid \mathcal{F}_{t}\right] \\
& =\frac{T_{-t} p_{x}[S(T)]}{g} E_{Q_{T}}\left[\left(a_{x r}(T)-g\right)^{+} \mid \mathcal{F}_{t}\right]
\end{aligned}
$$

The last line follows from the numeraire martingale result, equation (4), because replacing $V(T)$ with $S(T)$ in that equation gives

$$
\frac{S(t)}{D(t, T)}=E_{Q_{T}}\left[S(T) \mid \mathcal{F}_{t}\right]
$$

Inserting the expression for $a_{x r}(T)$ from (2) we have

$$
E_{Q_{T}}\left[\left(a_{x r}(T)-g\right)^{+} \mid \mathcal{F}_{t}\right]=E_{Q_{T}}\left[\left(\sum_{j=1}^{J}{ }_{j} p_{x r} D(T, T+j)-g\right)^{+} \mid \mathcal{F}_{t}\right]
$$

The expression inside the expectation on the right hand side corresponds to a call option on a coupon paying bond where the 'coupon' payment at time $(T+j)$ is ${ }_{j} p_{x r}$. This 'coupon bond' has value at time, $T$ :

$$
\sum_{j=1}^{J}{ }_{j} p_{x r} D(T, T+j)
$$

The market value at time, $t$ of this coupon bond is

$$
P(t)=\sum_{j=1}^{J} p_{x r} D(t, T+j) .
$$

So $P(t)$ is the value of a deferred annuity, but without allowance for mortality during deferment. With this notation our call option has a value at time, $T$ of $(P(T)-g)^{+}$. The numeraire approach is described more fully in Björk (1998).

\subsection{Using Jamshidian's method for coupon bond options}

Jamshidian (1989) showed that if the interest rate follows a one-factor process, then the market price of the option on the coupon bond with strike price $g$ is equal to the price of a portfolio of options on the individual zero coupon 
bonds with strike prices $K_{j}$, where $\left\{K_{j}\right\}$ are equal to the notional zero coupon bond prices to give an annuity $a_{x r}(T)$ with market price $g$ at $T$. That is, let $r_{T}^{*}$ denote the value of the short rate for which

$$
\sum_{j=1}^{J}{ }_{j} p_{x r} D^{*}(T, T+j)=g
$$

where we use the asterisk to signify that each zero coupon bond is evaluated using short rate $r_{T}^{* 7}$. Then set

$$
K_{j}=D^{*}(T, T+j) .
$$

Then the call option with strike $g$ on the coupon bond $P(t)$ can be valued as

$$
C[P(t), g, t]=\sum_{j=1}^{J} p_{x r} C\left[D(t, T+j), K_{j}, t\right],
$$

where $C\left[D(t, T+j), K_{j}, t\right]$ is the price at time $t$ of a call option on the zero coupon bond with maturity $(T+j)$ and strike price $K_{j}$.

We can use the call option $C[P(t), g, t]$ to obtain an explicit expression for the GAO value at $t, G(t)$. Recall that

$$
G(t)=\frac{T-t}{g} p_{x} S(T) E_{Q_{T}}\left[(P(T)-g)^{+} \mid \mathcal{F}_{t}\right] .
$$

From the numeraire valuation equation we have

$$
\frac{C[P(t), g, t]}{D(t, T)}=E_{Q_{T}}\left[(P(T)-g)^{+} \mid \mathcal{F}_{t}\right]
$$

Pulling all the pieces together we have

$$
G(t)=\frac{T-t}{p_{x} S(t)} \sum_{j}^{J} \frac{\sum_{j=1 j} p_{x r} C\left[D(t, T+j), K_{j}, t\right]}{D(t, T)} .
$$

\subsection{Applying the Hull-White interest rate model}

Jamshidian's result requires a one-factor interest rate model. We use a version of the Hull-White (1990) model. This model is also known as extended Vasicek, from the Vasicek (1977) model.

The short rate of interest at $t$ is assumed to follow the process:

$$
d r(t)=\kappa(\theta(t)-r(t)) d t+\sigma d W_{t}
$$

\footnotetext{
7 In a one-factor model, setting the short rate determines the entire term structure.
} 
where $\theta(t)$ is a deterministic function determined by the initial term structure of interest rates. Using the function $\theta(t)$ enables us to match the model term structure and the market term structure at the start of the projection.

Björk (1998) gives the formula for the term structure at $t$, using the market term structure at initial date $t=0$, as:

$D(t, T)=\frac{D(0, T)}{D(0, t)} \exp \left\{B(t, T) f^{*}(0, t)-\frac{\sigma^{2}}{4 \kappa} B(t, T)^{2}\left(1-e^{-2 \kappa t}\right)-B(t, T) r(t)\right\}$

where $f^{*}(0, t)$ is the $t$-year continuously compounded forward rate at $t=0$, and

$$
B(t, T)=\frac{1}{\kappa}\left\{1-e^{-\kappa(T-t)}\right\}
$$

This formula can be used to identify the strike price sequence $\left\{K_{j}\right\}$ from equation (7), and also used to value the option for given values of $r(t)$.

The explicit formula for each individual bond option under the Hull-White model is

$$
C\left[D(t, T+J), K_{j}, t\right]=D(t, T+j) N\left(h_{1}(j)\right)-K_{j} D(t, T) N\left(h_{2}(j)\right),
$$

where

and

$$
\begin{aligned}
& h_{1}(j)=\frac{\log \frac{D(t, T+j)}{D(t, T) K_{j}}}{\sigma_{P}(j)}+\frac{\sigma_{P}(j)}{2}, \\
& h_{2}(j)=\frac{\log \frac{D(t, T+j)}{D(t, T) K_{j}}}{\sigma_{P}(j)}-\frac{\sigma_{P}(j)}{2},
\end{aligned}
$$

$$
\sigma_{P}(j)=\sigma \sqrt{\frac{1-e^{-2 \kappa(T-t)}}{2 \kappa}} \frac{\left(1-e^{-\kappa j}\right)}{\kappa} .
$$

The parameters $\kappa$ and $\sigma$ characterize the dynamics of the short rate of interest under the Hull-White process.

\section{Valuation of the Guaranteed Annuity Option}

In this section we will derive the historical time series of market values for the guarantee based on the formula derived in the last section. It would have been helpful if the UK insurance companies had computed these market values at regular intervals since they would have highlighted the emergence of the liability under the guaranteed annuity option. The technology for pricing interest rate options was in its infancy in 1980 but by 1990 the models we use were in the public domain. An estimate of the market value of the guarantee can 
be derived from the one-factor stochastic interest rate model. We will use the model to estimate the value of the guarantees for the period 1980-2002.

In the previous section we derived a formula for the market price of the guaranteed annuity option using the Hull-White model. A similar formula has also been derived by Ballotta and Haberman (2002). They start from the Heath Jarrow Morton model and then restrict the volatility dynamics of the forward rate process to derive tractable formulae.

We used the following parameter estimates to compute the market values of the guaranteed annuity option

\begin{tabular}{|cc|}
\hline Parameter & Value \\
\hline$\kappa$ & 0.35 \\
$\sigma$ & 0.025 \\
\hline
\end{tabular}

These parameters are broadly comparable with estimates that have been obtained in the literature based on UK data for this time period. See Nowman (1997) and Yu and Phillips (2001).

Figure 3 illustrates how the market value of the option as percentage of the current fund value changes over time. We assume that the option has remaining time to maturity of ten years and that $x r=65$ so that the age of the policyholder at the option valuation date is $x=55$. We ignore the impact of lapses and expenses and we assume that all policyholders will take up the option at maturity if it is in their interest. The term structure at each date is obtained by assuming that the $2.5 \%$ consol yield operates for maturities of five years and longer. Yields for maturities one to five are obtained by a linear interpolation between the Treasury Bill rate and the five year rate. While this procedure does not give the precise term structure at a given time it captures the shape of the term structure at that time.

We assume two different mortality models, a(55), representing the outdated mortality in common use in the 1980s, and PMA92(C20), representing a reasonable mortality assumption for contracts on lives currently age 55 .

Figure 3 shows the very substantial effect of the mortality assumption. By comparison with Figure 2, we see a very similar pattern of liability, but instead of considering the maturity value of the contract, known only at the retirement age, this figure plots the option value ten years before retirement. The similarity of these two figures shows that the simple Hull-White model may be useful for determining the market price of the option, even with the simplifying assumption of independence of stock prices and interest rates.

Figure 4 illustrates how the cost of the guaranteed annuity option for our benchmark contract varies with the volatility assumption. We used three different volatility assumptions: $\sigma=.015, .025, .035$. The market values are relatively insensitive to the volatility assumption for long periods. Indeed the only periods where we can distinguish the three separate curves corresponds to periods when the long-term interest rate is close to the strike price of the option. We know from basic Black Scholes comparative statics that the sensitivity of an option value to the volatility is highest when the underlying asset 


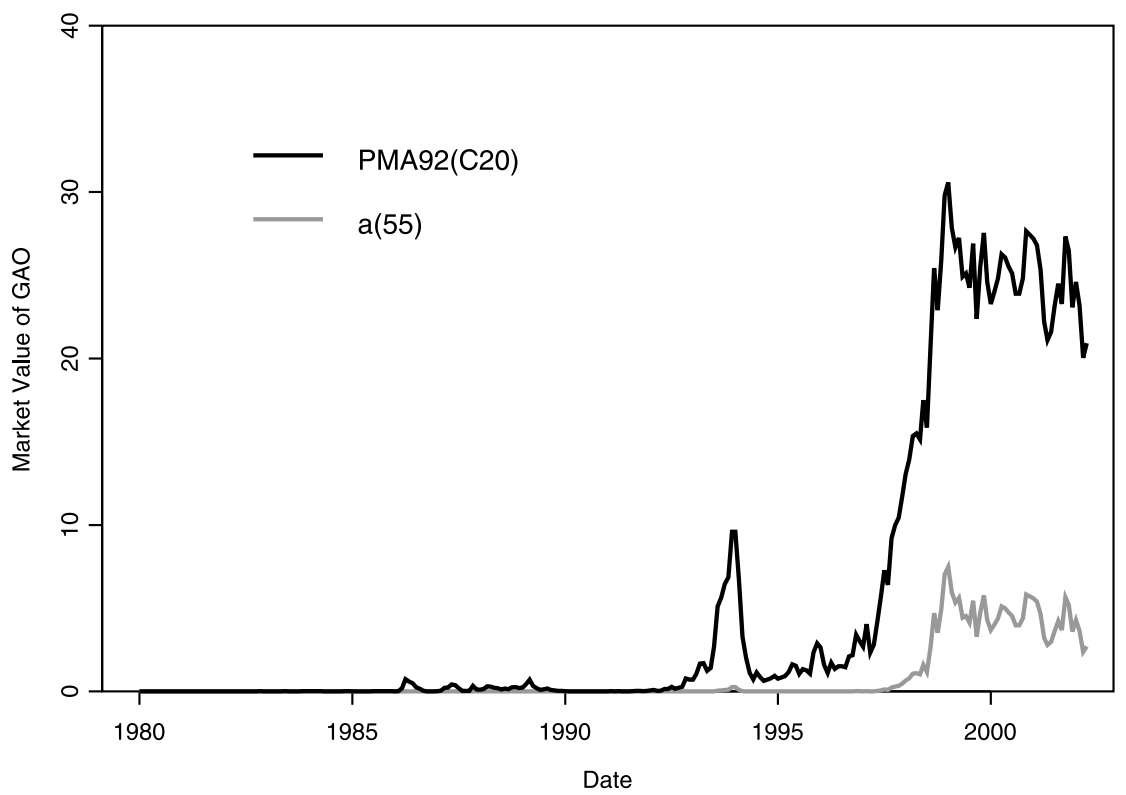

Figure 3: Historical market values of GAO with 10 years to maturity, using a(55) and PMA92(C20) mortality, per $£ 100$ of current portfolio value. Stock prices are assumed to be independent of interest rates. Hull-White model parameters $\kappa=0.35, \sigma=.025$.

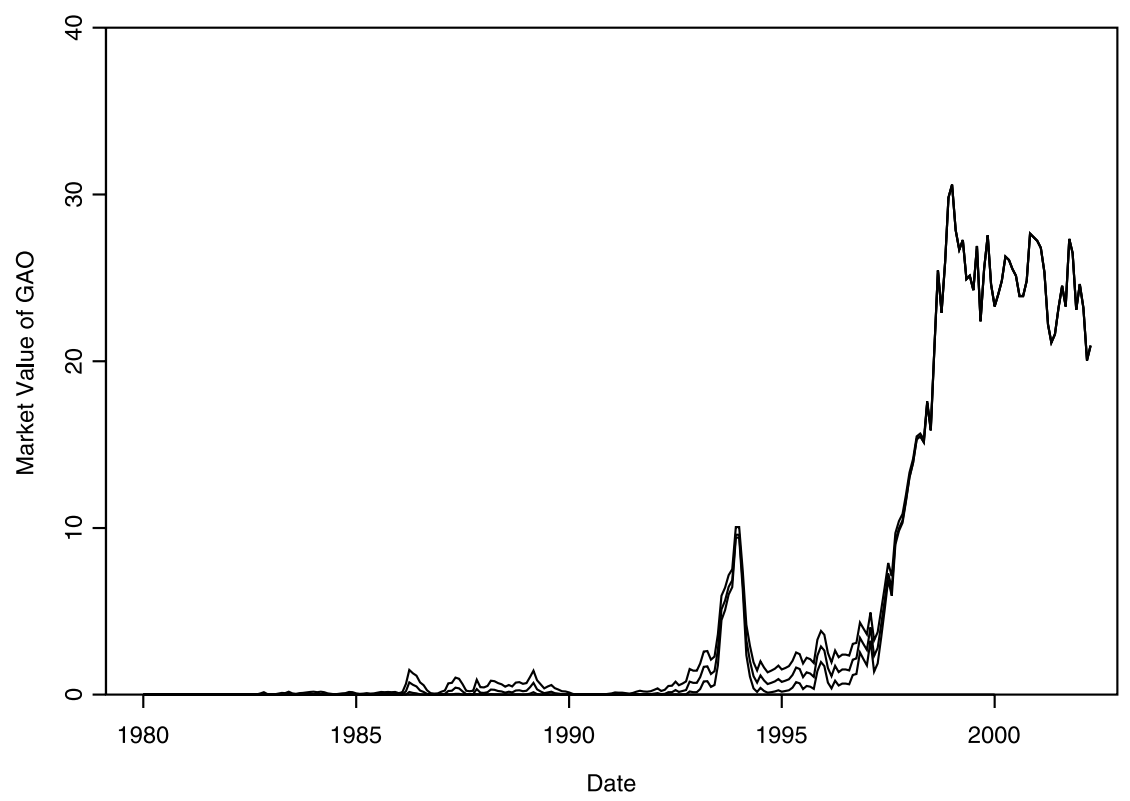

Figure 4: Market values of GAO with 10 years to maturity using $\sigma=0.015,0.025,0.035$; cost per $£ 100$ current portfolio value. Stock prices are assumed to be independent of interest rates. $\kappa=0.35$; PMA92(C20) mortality. 


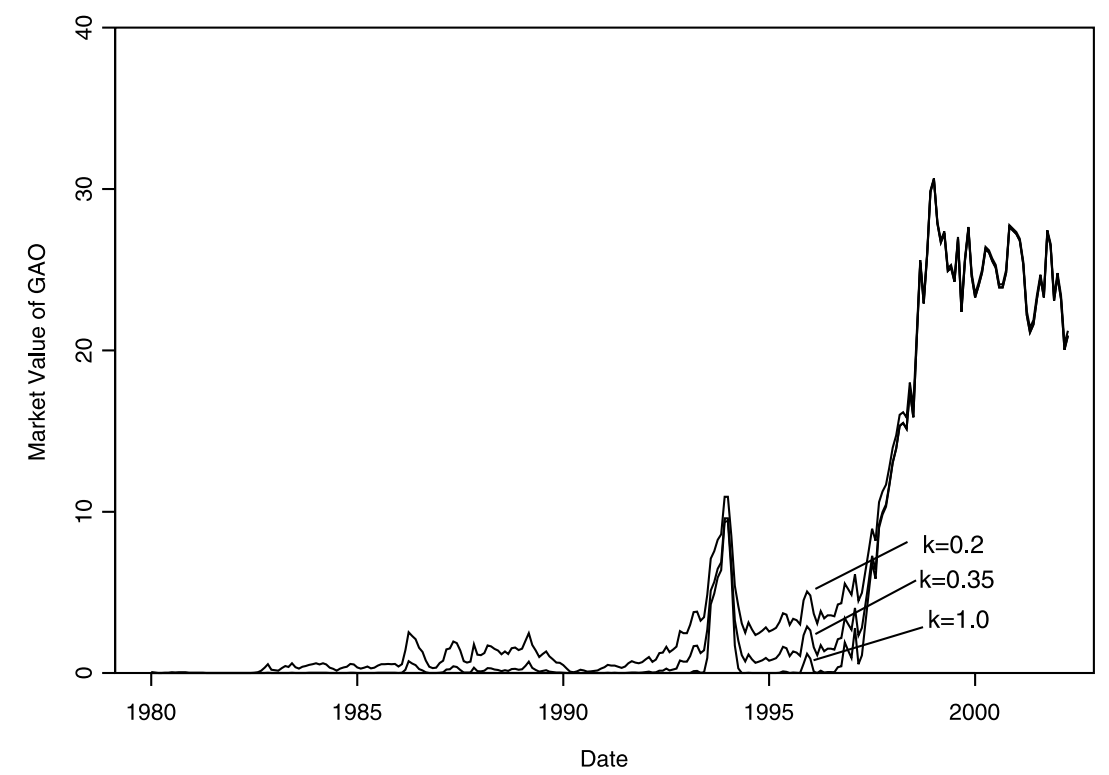

Figure 5: Market values of GAO with 10 years to maturity using $\kappa=0.2,0.35,1.00$; cost per $£ 100$ current portfolio value. Stock prices are assumed to be independent of interest rates. $\sigma=0.025$; PMA92(C20) mortality.

price is close to the strike price. If the option is very far out of the money or deeply in the money the price of the option is relatively insensitive to the volatility assumption. This same intuition is at work here.

The option value also depends on the assumed value of the autoregression factor $\kappa$. Figure 5 shows how the cost varies with three values; $\kappa=0.2,0.35$ and, 1.0. Holding everything else equal, smaller values for $\kappa$ lead to an increase in the option price. This is because as $\kappa$ decreases the overall volatility increases - periods of low interest are more likely to be prolonged with high autocorrelation - and higher volatility causes the option price to increase. Note that for $\kappa=0.2$ the GAO price is much larger than the benchmark value (based on $\kappa=0.35$ ) for the out-of-the-money case.

At first sight it may be surprising that a simple one-factor model can give at least an approximate estimate of the market value of the option (per $£ 100$ portfolio value), since actual interest rate dynamics are much too complicated to be captured by such a model. One reason is that we have calibrated the model to the input term structure so that it reproduces the market prices of all the zero coupon bonds. In addition the prices are fairly robust to the volatility assumption for the realized market conditions, though possibly less robust to the autoregression assumptions, particularly for the out-of-the-money periods. However we stress that such a simple model will not be adequate for hedging purposes. Hull (2002) notes

"The reality is that relatively simple one-factor models, if used carefully, usually give reasonable prices for instruments, but good hedging schemes must explicitly or implicitly assume many factors." 


\section{Hedging}

In this section we discuss some of the issues involved in hedging the guaranteed annuity risk using traded securities. Although the full fledged guaranteed annuity option depends on three stochastic variables - interest rates, stock prices and mortality - here we just discuss the interest rate risk.

The hedging of long-term interest rate options is a difficult task. In order to implement an effective hedging strategy we require a robust and reliable model of interest rate dynamics over the long-term. The search for such a model remains an area of active research and, despite some useful progress, there appears to be no consensus on such a model. For a survey of some of the recent work in modelling term structure dynamics see Dai and Singleton (2003). Note that for risk management and hedging purposes we require a model that provides a good description of the actual movements in yield curves over time. In other words we need a model that describes interest rate movements under the real world measure. For pricing we only needed the $Q$-measure, with parameters determined from the current market structure.

We begin by reviewing the relationship between pricing and hedging in an ideal setting. Consider the standard no arbitrage pricing model, where there is a perfect frictionless market with continuous trading. If the market is complete, then any payoff can be hedged with traded securities. Since there is no arbitrage the current price of the derivative must be equal to the current price of the replicating portfolio. If an institution sells this derivative then it can take the premium (price) and set up the replicating portfolio. As time passes it can dynamically adjust the position, so that at maturity the value of the replicating portfolio is exactly equal to the payoff on the derivative. In an ideal world where the model assumptions are fulfilled, it should be possible to conduct this replication program without needing any additional funds. The initial price should be exactly sufficient.

In the real world the assumptions of these models are never exactly fulfilled. For example

- The asset price dynamics will not be correctly specified.

- It will not be feasible to rebalance the replicating portfolio on a continuous basis. Instead it has to be rebalanced at discrete intervals.

- There are transaction costs on trading.

The impact of these deviations from the idealized assumptions has been explored in the Black Scholes Merton world. We discuss these three possible deviations in turn.

If the process that generates the market prices deviates from the model implicit in the pricing formula there will be additional hedging errors. This is because the portfolio weights that would be required to replicate the payoff under the true model will be different from the portfolio weights computed under the assumed model. This point has been explored in the case of equity derivatives by several authors including Bakshi, Cao and Chen (1997, 2000), Chernov et al (2001) and Jiang and Oomen (2002), and in the case of equitylinked life insurance by Hardy (2003). 
With discrete rebalancing, Boyle and Emanuel (1980) showed that if the portfolio is rebalanced at discrete intervals, there will be a hedging error which tends to zero as the rebalancing becomes more frequent. In the presence of transaction costs the frequency of rebalancing involves a trade-off between the size of the hedging error and the trading costs.

However in practice we may emphasize pricing at the expense of hedging by calibrating an incorrect model to give the accurate market price of a derivative. For example, quoted swaption and cap prices are universally based on the simple Black model. The Black model volatility that makes the market price equal to the model price has become a standard measure for conveying the price. However the Black model does not provide realistic dynamics for interest rates and so it is unsuitable for hedging and risk management applications. In the same way stock option prices when the asset price dynamics follow a process with stochastic volatility can still be quoted in terms of the Black Scholes implied volatility. We can always find the value of the Black Scholes volatility that reproduces the market price of the option even when the true dynamics include stochastic volatility. However as shown by Melino and Turnbull (1995) the use of the simple Black Scholes model, in the presence of stochastic volatility, may lead to large and costly hedging errors, especially for long dated options.

In the case of stochastic interest rates, several studies have shown that it is possible to have a simple model that does a reasonable job of pricing interest rate derivatives even though the model is inadequate for hedging purposes. Canabarro (1995) uses a two factor simulated economy to show that, although one-factor models produce accurate prices for interest rate derivatives, these models lead to poor hedging performance. Gupta and Subrahmanyam (2001) use actual price data to show that, while a one-factor model is adequate for pricing caps and floors, a two factor model performs better in hedging these types of derivatives.

Litterman and Scheinkman (1991) demonstrated that most of the variation in interest rates could be explained by three stochastic factors. Dai and Singleton (2000) examine three factor models of the so called affine class. The classical Cox Ingersoll Ross (1985) model and the Vasicek model are the best known examples of the affine class. These models have the attractive property that bond prices become exponentials of affine functions and are easy to evaluate. Dai and Singleton find reasonable empirical support for some versions of the three factor affine model using swap market data for the period April 1987 to August 1996.

In the context of guaranteed annuity options we require an interest rate model that describes interest rate behavior over a longer time span. Ahn, Dittmar and Gallant (2002) provide support for quadratic term structure models. They are known as quadratic models because the short term rate of interest is a quadratic function of the underlying state variables. Their empirical tests use US bond data for the period 1946-1991 and they conclude that the quadratic three factor model

“...provides a fairly good description of term structure dynamics and captures these dynamics better than the preferred affine term structure model of Dai and Singleton." 
Bansal and Zhou (2002) show that the affine models are also dominated by their proposed regime switching model. Their empirical test is based on US interest rate data for the period 1964-1995. Even a casual inspection of the data suggests the existence of different regimes. They conclude that standard models, including the affine models with up to three factors, are sharply rejected by the data. Regime switching models have been extensively used by Hardy (2003) to model equity returns in the context of pricing and risk management of equity indexed annuities.

The interest rate exposure in a guaranteed annuity option is similar to that under a long dated swaption. Hence it is instructive to examine some recent results on hedging swaptions. This is a topic of current interest as evidenced by papers by Andersen and Andreasen (2002), Fan, Gupta and Ritchken (2001), Driessen, Klaasen and Melenberg (2002), and Longstaff, Santa-Clara and Schwartz (2001). The main conclusion of these papers is that multi-factor models are necessary for good hedging results. However it should be noted that the empirical tests in these papers tend to use relatively short observation periods - around three to five years being typical. Swaption data is unavailable for long periods since the instruments first were created in the late 1980's. Hence these models are being tested over the 1995-2000 period when interest rates were fairly stable. If the swaption data were available over longer periods, it seems likely that a regime switching interest rate model would be required to do an adequate hedging job.

In Section 6 we consider the GAO hedge using highly simplified assumptions for equities and interest rates.

\section{THE EQUITY RISK}

We have already shown in equation (1) that the size of the payoff on the UK guaranteed annuity option is proportional to the amount of the maturity proceeds. This amount will depend on the stock market performance over the life of the contract. For unit-linked policies the maturity amount depends directly on the performance of the underlying fund. In the case of with profits contracts the policy proceeds depend on the bonuses declared by the insurance company and the size of these bonuses is directly related to stock market performance. In general the stock market returns are passed through to the policyholders in reversionary and terminal bonuses. In this section we discuss how the inclusion of equity risk impacts the pricing and risk management of the guaranteed annuity options.

We have seen in Section 3 that under some strong assumptions about the joint dynamics of interest rates we can obtain simple pricing formula. Specifically if we assume that equity returns are independent of interest rates, and that interest rates are governed by a one-factor Hull-White model, we can obtain a simple valuation formula for the price of the guaranteed annuity option. The formula can be modified to handle the case when there is correlation between stocks and bonds. Ballotta and Haberman have also derived a formula under these assumptions. 
We can illustrate the key issues involved in pricing and hedging when the equity risk is included by considering a simpler contract than the guaranteed annuity option. This contract has the following payoff at time $T$

$$
P(T, T+j)=S(T) \max \left(D(T, T+j)-K_{j}, 0\right)
$$

It corresponds to an option on the zero coupon bond which matures at time $(T+j)$ and where the payoff is directly related to the value of the reference index. This contract includes no mortality risk here and there is just one zero coupon bond at maturity rather than a linear combination of zero coupon bonds. However this simpler contract captures the key dependencies of the guaranteed annuity option. The full guaranteed annuity option with correlation can then be determined, using $D(t, T)$ as numeraire, and the forward measure $Q_{T}$ as the equivalent martingale measure:

$$
V(t)=D(t, T) \sum_{j=1}^{J}{ }_{T+j-t} p_{x} E_{Q_{T}}[P(T, T+j)]
$$

We can derive a closed form expression for each term in $V(t)$ if, for example, we assume that under the forward measure $Q_{T}$ the random variables $S(T)$ and $D(T, T+j)$ have a bivariate lognormal distribution.

For simplicity we treat the period from $t$ to $T$ as a single time step, with variance-covariance matrix for $\log S(T) \mid \mathcal{F}_{t}$ and $\log D(T, T+j) \mid \mathcal{F}_{t}$ :

$$
\Sigma_{\mathbf{j}}=\left[\begin{array}{cc}
\sigma_{S}^{2} & \rho \sigma_{D} \sigma_{S} \\
\rho \sigma_{D} \sigma_{S} & \sigma_{D}^{2}
\end{array}\right] .
$$

Note that the values of $\rho$ and $\sigma_{D}$ would both vary with $j$.

Assume also that under the forward measure $Q_{T}$ the means of $\log S(T) / S(t) \mid$ $\mathcal{F}_{t}$ and $\log D(T, T+j) / D(t, T+j) \mid \mathcal{F}_{t}$ are $\mu_{S}$ and $\mu_{D}$ respectively.

From the martingale numeraire property, we know that

$$
E_{Q_{T}}\left[\frac{D(T, T+j)}{D(T, T)} \mid \mathcal{F}_{t}\right]=\frac{D(t, T+j)}{D(t, T)}
$$

and from the lognormal distribution we know

$$
E_{Q_{T}}\left[D(T, T+j) \mid \mathcal{F}_{t}\right]=D(t, T+j) e^{\mu_{D}+\sigma_{D}^{2} / 2}
$$

so that

$$
e^{\mu_{D}+\sigma_{D}^{2} / 2}=\frac{1}{D(t, T)}
$$

Similarly, $e^{\mu_{S}+\sigma_{S}^{2} / 2}=\frac{1}{D(t, T)}$ 
This is analogous to the risk-free property in a standard Black-Scholes framework, that all assets have the same expected accrual under the $Q$-measure.

Using properties of the bivariate lognormal distribution (see, for example, chapter four of Boyle et al (1998)), we have

$$
\begin{gathered}
E_{Q_{T}}\left[P(T, T+j) \mid \mathcal{F}_{t}\right]= \\
S(t) e^{\mu_{S}+\sigma_{S}^{2} / 2}\left\{D(t, T+j) e^{\mu_{D}+\sigma_{D}^{2} / 2+\rho \sigma_{S} \sigma_{D}} N\left(h_{3}\right)-K_{j} N\left(h_{4}\right)\right\} \\
=\frac{S(t)}{D(t, T)}\left\{\frac{D(t, T+j)}{D(t, T)} e^{\rho \sigma_{S} \sigma_{D}} N\left(h_{3}\right)-K_{j} N\left(h_{4}\right)\right\} \\
\text { where } h_{3}=\frac{\log \frac{D(t, T+j)}{D(t, T) K_{j}}+\rho \sigma_{D} \sigma_{S}}{\sigma_{D}}+\frac{\sigma_{D}}{2} \text { and } h_{4}=h_{3}-\sigma_{D}
\end{gathered}
$$

So the option price at $t$ for the annuity payment at $T+j$ is

$$
{ }_{T+j-t} P_{x} S(t)\left\{\frac{D(t, T+j)}{D(t, T)} e^{\rho \sigma_{S} \sigma_{D}} N\left(h_{3}\right)-K_{j} N\left(h_{4}\right)\right\}
$$

Formula (12) incorporates both equity risk and interest rate risk. The fact that the option is proportional to the equity $S(t)$ arises because it is a form of quanto option, where the payoff is essentially in units of stock rather than in cash. Wilkie et al (2003) discuss this quanto feature. The moneyness of the option is entirely related to the interest rate risk. Once the option is in the money, then every extra $£$ of stock accumulation increases the cost of the GAO proportionately. This leads to perverse incentives for the insurer acting as fund manager.

We see that the option price is an increasing function of the correlation coefficients $\rho$. Indeed the price is quite sensitive to the values of $\rho$ and for plausible parameter values the option price with $\rho=0$ is roughly double that using $\rho=-1$, and is around one-half the price using $\rho=1$, for all $j$. Correlations are notoriously difficult to forecast and so we conclude that when the equity risk is assumed to be correlated with the interest rate risk, pricing the option becomes more difficult. Of course this modifies our earlier conclusions about the effectiveness of a one-factor model in pricing the guaranteed annuity option. Our earlier model assumed that the stock price movements were independent of interest rate movements.

It is now well established in the empirical literature that equity prices do not follow a simple lognormal process. There is mounting evidence that some type of stochastic volatility model does a better job of modelling equity returns. Hardy (2003) provides evidence that regime switching model does a good job of fitting the empirical distribution of monthly stock returns. Andersen Benzoni and Lund (2002) demonstrate that both stochastic volatility and jump components are present in the $\mathrm{S} \& \mathrm{P}$ daily index returns. Several authors ${ }^{8}$ have

8 See Bakshi, Cao and Chen (1997, 2000). 
shown that these models may produce significant pricing deviations from the lognormal Black Scholes option prices. This deviation depends to some extent on the moneyness and the term of the option. It will be less critical for shorter, in-the-money options which are not very sensitive to the volatility.

When we turn to hedging matters become worse. There are two reasons. First we require a good model of the joint dynamics of bonds and equities that will be robust over long time periods. There appears to be no obvious model that would fulfill these requirements. The lognormal assumption for the zero coupon bond prices is a particular problem when, in practice, these prices are highly auto-correlated. Second even if we are willing to adopt the pricing model in (12) the resulting hedging implementation leads to some practical problems.

To hedge the option based on this simple model we would need to invest in three securities. The first is an investment in the underlying equity index equal to the current market value of the option. We denote the number of units invested in the index by $H_{1}(t)$ where

$$
H_{1}(t)=\left(\frac{D(t, T+j) e^{\rho \sigma_{D} \sigma_{S}}}{D(t, T)} N\left(h_{3}\right)-K_{j} N\left(h_{4}\right)\right)
$$

The second consists of an investment of $H_{2}(t)$ units of the zero coupon bond which matures at time $(T+j)$, where

$$
H_{2}(t)=S(t) \frac{e^{\rho \sigma_{D} \sigma_{S}}}{D(t, T)} N\left(h_{3}\right)
$$

The third consists of an investment of $H_{3}(t)$ units of the zero coupon bond which matures at time $(T)$, where

$$
H_{3}(t)=-S(t) \frac{D(t, T+j) e^{\rho \sigma_{D} \sigma_{S}}}{D(t, T)^{2}} N\left(h_{3}\right)
$$

Note that the value of the initial hedge is

$$
H_{1}(t) S(t)+H_{2}(t) D(t, T+j)+H_{3}(t) D(t, T)=S(t) H_{1}(t),
$$

which is equal to the initial price of the option since the last two terms on the left hand side cancel one another.

Suppose the hedge is to be rebalanced at time $(t+h)$. Just before rebalancing the value of the hedge portfolio is

$$
H_{1}(t) S(t+h)+H_{2}(t) D(t+h, T+j)+H_{3}(t) D(t+h, T)
$$

where $S(t+h), D(t+h, T+j), D(t+h, T)$ denote the market prices at time $(t+h)$ of the three hedge assets. The new hedging weights $H_{i}(t+h), i=1,2,3$ are computed based on these new asset prices and the value of the revised hedge is 


$$
H_{1}(t+h) S(t+h)+H_{2}(t+h) D(t+h, T+j)+H_{3}(t+h) D(t+h, T) .
$$

If the value of the hedge portfolio after rebalancing increases funds need to be added. If the value of the hedge portfolio after rebalancing goes down funds can be withdrawn. In an idealized world the hedge would be self financing. However in practice hedging is done discretely, there are transactions costs and the market movements can deviate significantly from those implied by the model. These slippages can lead to considerable hedging errors. Some numerical examples using a similar approach are given in Hardy (2003).

\section{The Mortality Risk}

We noted earlier that there was a dramatic improvement in annuitants mortality over the relevant period. This improvement was not anticipated when the contracts were designed. The effect of this improvement was to increase the value of the interest rate guarantee by raising the threshold interest rate at which the guarantee became effective. The structure of the guaranteed annuity option means that the policyholder's option is with respect to two random variables: future interest rates and future mortality rates. To isolate the mortality option, suppose that all interest rates are deterministic but that future mortality rates are uncertain. In this case the option to convert the maturity proceeds into a life annuity is an option on future mortality rates. If, on maturity, the mortality rates have improved ${ }^{9}$ above the level assumed in the contract the policyholder will obtain a higher annuity under the guarantee. On the other hand if life expectancies are lower than those assumed in the contract the guarantee is of no value since policyholder will obtain a higher annuity in the open market. When interest rates are stochastic the mortality option interacts with the interest rate option as we saw in Section Two.

Milevsky and Promsilow (2001) have recently analyzed the twin impacts of stochastic mortality and stochastic interest rates in their discussion of guaranteed purchase rates under variable annuities in the United States. They model the mortality option by modeling the traditional actuarial force of mortality as a random variable. The expectation of this random variable corresponds to the classical actuarial force of mortality. They show that, under some assumptions, the mortality option can - in principle - be hedged by the insurance company selling more life insurance. The intuition here is that if people live longer the losses on the option to annuitize will be offset by profits on the life policies sold.

There may be some practical difficulties in implementing this. First, it may not be possible to sell the insurance policies to the same type of policyholders who hold the GAO contracts. Secondly, to implement the mortality hedging strategy the insurer requires a good estimate of the distribution of future mortality. Harking back to the UK case it would have been most unlikely for any

9 When we write about mortality rates improving we mean that people are living longer. 
insurer in the 1970's to predict accurately the distribution of future mortality rates. If the insurer has a sufficiently accurate estimate of the distribution of the future mortality rates to conduct an effective hedging strategy, then it should be able to project future mortality improvements to minimize the mortality risk under the guarantee.

The mortality risk exposure facing insurers under the guaranteed annuity options could have been eliminated at inception by a different contract design. Instead of guaranteeing to pay a fixed annual amount the insurer could have guaranteed to use a certain pre specified interest rate in conjunction with the prevailing mortality assumption (in use at the time of retirement). Under this revised contract design there is no additional liability incurred if mortality improves and annuities become more expensive. This adjustment would have significantly reduced the liabilities under the guaranteed annuity options.

\section{Hedging with Swaptions}

Swaps have became enormously important financial instruments for managing interest rate risks. They are often more suitable than bonds for hedging interest rate risk because the swap market is more liquid. Furthermore, while it can be difficult to short a bond, the same exposure can easily be arranged in the swap market by entering a payer swap. Options to enter swap contracts are known as swaptions and there is now a very liquid market in long dated swaptions, where the option maturities can extend for ten years and the ensuing swap can last for periods up to thirty years. Pelsser (2003) shows that long dated receiver swaptions are natural vehicles for dealing with the interest rate risk under guaranteed annuity options. In this section we discuss the feasibility of using this approach.

Upon maturity, the owner of the swaption will only exercise it if the option is in the money. Suppose the swaption gives its owner the option to enter a receiver swap when the swaption matures. The counter party that enters (or is long) a receiver swap agrees to pay the floating interest rate (e.g. Libor or Euribor) and in return receive the fixed rate: known as the swap rate. If a firm owns a receiver swaption with a strike price of $7 \%$ it will compare the market swap rate with the strike rate when the swaption reaches maturity. For example if the market swap rate at maturity is $5 \%$ then the firm should optimally exercise the swaption because the guaranteed rate of $7 \%$ provides a better deal. It is preferable to receive fixed rate coupons of $7 \%$ than the market rate of 5\%. By entering a receiver swaption an institution protects itself against the risk that interest rates will have fallen when the swaption matures. This is exactly the type of interest rate risk exposure in the guaranteed annuity option.

Pelsser shows how to incorporate mortality risk to replicate the expected payoff under the guaranteed annuity option. He assumes, as we do, that the mortality risk is independent of the financial risk and that the force of mortality (hazard rate) is deterministic. He derives an expression for the price of the guaranteed annuity option as a portfolio of long dated receiver swaptions. The advantage of his approach is that the swaptions incorporate the right type 
of interest rate options. Pelsser calls this approach the static hedge since there is no need for dynamic hedging. This is an advantage given the difficulty of hedging long-term interest rate options with more basic securities such as bonds and swaps. However the swaption approach still has problems in dealing with the stock price risk and the risk of increasing longevity.

The presence of equity risk means that the number of swaptions has to be adjusted in line with index movements. During a period of rising equity returns an insurer would have to keep purchasing these swaptions and this would become very expensive as the swaptions began to move into the money. In these circumstances the liability under the guarantee is open ended. The swaption solution does not deal with the equity risk.

\section{LESSONS}

We have discussed the three major types of risks in the guaranteed annuity option and examined the pricing and the feasibility of hedging the risk under these contracts. In this section we will explore the extent to which the approaches discussed in his paper could or should have been applied. We also suggest that this episode has implications for the eduction and training of the actuarial profession particulary in connection with its exposure to ideas in modern financial economics.

It is worth emphasizing that when these guarantees were being written, the UK actuarial profession was still using deterministic methods to value liabilities. In particular valuation and premium calculations were based on a single deterministic interest rate. These methods were enshrined in the educational syllabus and rooted in current practice. Such methods are incapable of dealing adequately with options.

The relevant UK actuarial textbook used at the time, Fisher and Young (1965) in discussing guaranteed annuity options stated:

"If, when the maturity date arrives, the guaranteed annuity rate is not as good as the office's own rates or a better purchase can be made elsewhere the option will not be exercised. The office cannot possibly gain from the transaction and should, therefore, at least in theory, guarantee only the lowest rate that seem likely in the foreseeable future.

However no guidance was provided as to what level this rate should be. Fisher and Young did suggest that conservative assumptions should be used and that allowance should be made for future improvements in mortality.

"The option may not be exercised until a future date ranging perhaps from 5 to 50 years hence, and since it will be relatively easy to compare the yield under the option with the then current yields it is likely to be exercised against the office. The mortality and interest rate assumptions should be conservative."

The standard actuarial toolkit in use at the time was incapable of assessing the risks under this type of guarantee. However the guarantees were granted and 
they gave rise to a serious risk management problem that jeopardized the solvency of a number of UK companies. For many companies, the first time that the guaranteed annuity option for maturing contract became in-the-money was in October 1993. In December 1993, Equitable Life announced that it would cut the terminal bonuses in the case of policyholders who opted for the guarantee. This meant that the guaranteed annuity option policyholders who exercised their guarantee ended up paying for their own guarantee. The affected policyholders argued that Equitable's action made a mockery of their guarantee. The validity of this controversial approach became the subject of a protracted legal dispute. Eventually, in July 2000 the House of Lords settled the matter. It ruled against the Equitable and decreed that the practice of cutting the terminal bonuses to pay for the guarantee was disallowed. Equitable faced an immediate liability of 1.4 billion pounds to cover its current liability for the guaranteed annuity options and in December 2000 was forced to close its doors to new business. The oldest life insurance company in the world was felled by the guaranteed annuity option.

This entire episode should provide salutary lessons for the actuarial profession. It is now clear that the profession could have benefited from greater exposure to the paradigms of modern financial economics, to the difference between diversifiable and non-diversifiable risk, and to the application of stochastic simulation in asset-liability management would have enabled insurers to predict, monitor and manage the exposure under the guarantee.

\section{AcKNowledgments}

The authors thank Myung Chon, Antoon Pelsser and two anonymous referees for many very helpful comments.

\section{REFERENCES}

Ahn, D-H., Dittmar, R.F. and Gallant, A.R. (2002) Quadratic term structure models: theory and evidence. Review of Financial Studies 15, 243-288.

Andersen, L. and Andreasen, J. (2001) "Factor dependence in bermudan swaptions: fact or fiction?" Journal of Financial Economics 62 3-37.

Andersen, T.G., Benzoni, L. and Lund, J. (2002) An empirical investigation of continuous-time equity return models. Journal of Finance, 1239-1284.

BAKSHI, G., CAO, C. and CHEN, Z. (1997) Empirical performance of alternative option pricing models. Journal of Finance 52, 2003-2049.

Bakshi, G., Cao, C. and Chen, Z. (2000) Pricing and hedging long-term options. Journal of Econometrics 94, 277-318.

Ballotta, L. and Haberman, S. (2002) Valuation of guaranteed annuity options. Working Paper, Department of Actuarial Science and Statistics, City University, London, UK.

Bansal, R. and Zhou, H. (2002) Term structure of interest rates with regime shifts. Journal of Finance 57, 1997-2043.

BJÖRK, T. (1998) Arbitrage theory in continuous time. Oxford University Press.

Bolton, M.J., CARR, D.H., Collis, P.A. et al (1997) Reserving for annuity guarantees. Report of the Annuity Guarantees Working Party, Institute of Actuaries, London, UK. 
Boyle, P.P. and Emanuel, D. (1980) Discretely adjusted option hedges. Journal of Financial Economics 8, 259-282.

BOyle, P.P. and SchwarTz, E.S. (1977) Equilibrium prices of guarantees under equity-linked contracts, Journal of Risk and Insurance 44, 4, 639-660.

Boyle, P.P., Cox, S., Dufresne, D., Gerber, H., Mueller, H., Pedersen, H., Pliska, S., Sherris, M., Shiu, E. and TAN, K.S. (1998) Financial Economics. The Actuarial Foundation, Chicago, USA.

CANnABero, E. (1995) Where do one-factor interest rate models fail? Journal of Fixed Income 5, $31-52$.

Chernof, M., Gallant, A.R., Ghysels, E. and Tauchen, G. (2001) Alternative models for stock price dynamics. Working Paper, University of North Carolina.

Cox, J.C., Ingersoll, J.E. and Ross, S.A. (1985) A theory of the term structure of interest rates. Econometrica 53, 385-467.

DAI, Q. and Singleton, K. (2000) Specification analysis of affine term structure models. Journal of Finance 55, 1943-1978.

Dai, Q. and Singleton, K. (2003) Term structure dynamics in theory and reality. Review of Financial Studies, forthcoming.

Driessen, J., Klaassen, P. and Melenberg, B. (2003) The performance of multi-factor term structure models for pricing and hedging caps and swaptions, Journal of Financial and Quantitative Analysis, forthcoming.

Dunbar, N. (1999) Sterling Swaptions under New Scrutiny. Risk, December 33-35.

FAn, R., GuPTA, A. and RitchKen, P. (2001) On the performance of multi-factor term structure models for pricing caps and swaptions, Working Paper Case Western University, Weatherhead School of Management.

Fisher, H.F. and Young, J. (1965) Actuarial Practice of Life Assurance, Cambridge University Press.

Gupta, A. and Subrahmanyam, M.G. (2001) An Examination of the Static and Dynamic Performance of Interest Rate Option Pricing Models in the Dollar Cap-Floor Markets. Working Paper, Case Western Reserve University, Weatherhead School of Management.

HARDY, M.R. (2003) Investment Guarantees: Modeling and Risk Management for Equity-Linked Life Insurance, Wiley.

Hull, J. (2002) Options Futures and Other Derivatives, Prentice Hall.

Hull, J. and White A. (1990) "Pricing Interest Rate Derivative Securities", Review of Financial Studies 3(4), 573-592.

Jamshidian, F. (1989) “An Exact Bond Option Formula", Journal of Finance 44(1), 205-209.

JiAnG, G.J. and Oomen, R.C.A. (2002) Hedging Derivatives Risk, Working Paper, University of Arizona.

Litterman, T. and Scheinkman, J. (1991) Common factors affecting bond returns. Journal of Fixed Income 1, 62-74.

Longstaff, F., Santa-Clara, P. and Schwartz, E. (2001) Throwing Away a Billion Dollars. Journal of Financial Economics 63, 39-66.

Maturity Guarantees Working Party (MGWP) (1980) Report of the Maturity Guarantees Working Party. Journal of the Institute of Actuaries 107, 102-212.

Melino A. and S. Turnbull, M. (1995) Mis-specification and the Pricing and Hedging of longterm Foreign Currency Options. Journal of International Money and Finance 14.3, 373-393.

Milevsky, M.A., and Promislow, S.D. (2001) Mortality derivatives and the option to annuitize. Insurance: Mathematics and Economics 29(3), 299-316.

Nowman, K.B. (1997) Gaussian Estimation of Single-Factor Continuous Time Models of the Term Structure of Interest Rates. Journal of Finance 52, 1695-1706.

Pelsser, A. (2003) Pricing and Hedging Guaranteed Annuity Options via Static Option Replication. Insurance: Mathematics and Economics, forthcoming.

VASICEK, O.A. (1977) "An Equilibrium Characterization of the Term Structure". Journal of Financial Economics 5, 177-188.

Wilkie, A.D., Waters, H.R. and Yang, S. (2003) Reserving, Pricing and Hedging for Policies with Guaranteed Annuity Options. Paper presented to the Faculty of Actuaries, Edinburgh, January 2003. British Actuarial Journal, forthcoming. 
YAng, S. (2001) Reserving, Pricing and Hedging for Guaranteed Annuity Options. Phd Thesis,

Department of Actuarial Mathematics and Statistics, Heriot Watt University, Edinburgh.

YU, J. and Phillips, P. (2001) A Gaussian Approach for Continuous Time Models of the Short Term Interest Rates. The Econometrics Journal 4(2), 211-225.

\section{Phelim Boyle}

Centre for Advanced Studies in Finance

School of Accountancy

University of Waterloo

Waterloo, Ontario

Canada N2L $3 G 1$

MARY HARDY

Statistics and Actuarial Science

University of Waterloo

Waterloo, Ontario

Canada N2L $3 G 1$ 